\title{
Development time for initiating the mechanisms of electrical breakdown in vacuum
}

\author{
Grzegorz Twardosz ${ }^{1, *}$, Władysław Opydo ${ }^{2}$, and Kazimierz Bieliński ${ }^{2}$ \\ ${ }^{1}$ Poznan University of Technology, ul. Piotrowo 3A, 60-965 Poznań, Poland \\ ${ }^{2}$ UTP University of Science and Technology in Bydgoszcz, Al. prof. S. Kaliskiego 7, 85-796 Bydgoszcz, Poland
}

\begin{abstract}
The paper presents the development time of the slowest basic physical phenomena occurring in the mechanisms initiating the electrical breakdown in vacuum. The phenomena mentioned above are for the most part decisive for the delay in initiating the electrical breakdown.
\end{abstract}

\section{Introduction}

In order to initiate and develop an electrical breakdown in the high voltage vacuum-insulation system, the following conditions must exist [1]: electrons or other carriers of electric charge must be introduced into the inter-electrode space and a sufficient amount of gas or vapour particles must appear in that space, which, after ionization, will cause an increase in the value of current until short-circuit conditions are created. Here, an important role is played by several physical phenomena, which initiate the breakdown by interacting with each other. Some of these phenomena take place relatively slowly and their duration is much longer than that of others. Thus, they determine the delay in the occurrence of an electrical breakdown. Such a delay causes differences between the electric strengths of the vacuuminsulation system at d.c. voltage, a.c. voltage or surge voltage.

Hypotheses for mechanisms initiating the electrical breakdown in vacuum may be categorised as follows [1]: 1. Hypotheses which assume the field emission of an electron beam by the microprotrusion of a cathode, whereby the said electron beam bombards a certain part of the anode area.

2. Hypotheses which assume the motion of small charged lumps of material - micro-particles - through an inter-electrode gap under the influence of the electric field.

3. Hypotheses which assume the occurrence of a layer of adsorbed gases on the internal surfaces of the vacuum-insulation system. The discharge develops in gases desorbed from these surfaces.

\section{Basic dependencies}

The hypotheses for mechanisms initiating the electrical breakdown through field emission of electrons may, in turn, be divided into two groups. In the first group, it is believed that the determinant initiating the breakdown is the resistance heating of the microprotusion which emits the electron beam (the cathode mechanism), and in the second group, the heating of the anode area bombarded with the electron beam (the anode mechanism). The heating processes which are present here are characterised by the longest duration in the mechanisms initiating the electrical breakdown.

Dependencies of time constants of the heating of microprotrusions made of steel, copper or aluminium, with the shape of a truncated cone finished with a spherical cap, having three different values of the form factor, defined as the quotient of the value of microprotrusion base radius and the spherical cap radius which constitutes its finishing, that is: $g=r_{\mathrm{p}} / r$, are presented in Fig. 1 [2].

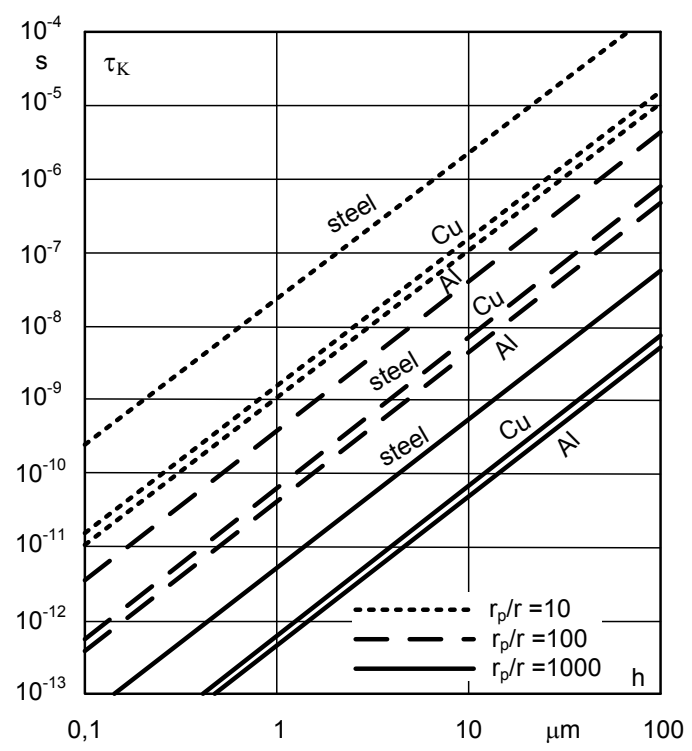

Fig. 1. Dependency of time constants for the heating of steel, copper or aluminium microprotrusions and the height of microprotrusions with different values of the form factor $g=r_{\mathrm{p} /} / r$ amounting to 10,100 and 1000 [2]

\footnotetext{
Corresponding author: grzegorz.twardosz@put.poznan.pl
} 
On the other hand, the dependencies of the time constants of the heating of the anode area (made of aluminium, steel and copper) bombarded with the electron beam, on the values of voltage at terminals of the vacuum-insulation system are presented in Fig.2 [1].

Micro-unevenness of the electrode surface of the high-voltage insulation system or a small lump of material, i.e. a micro-particle on that surface, with voltage at the system terminals, has a certain electric charge. Thus, it is affected by the electrostatic force, which may detach it from the electrode and cause its motion towards the opposite electrode. The effects of the motion of the micro-particles between the electrodes of the vacuum insulation system and their hitting against the surface of the opposite electrode have become the basic phenomena in several hypotheses regarding the initiation of the electrical breakdown in vacuum [1].

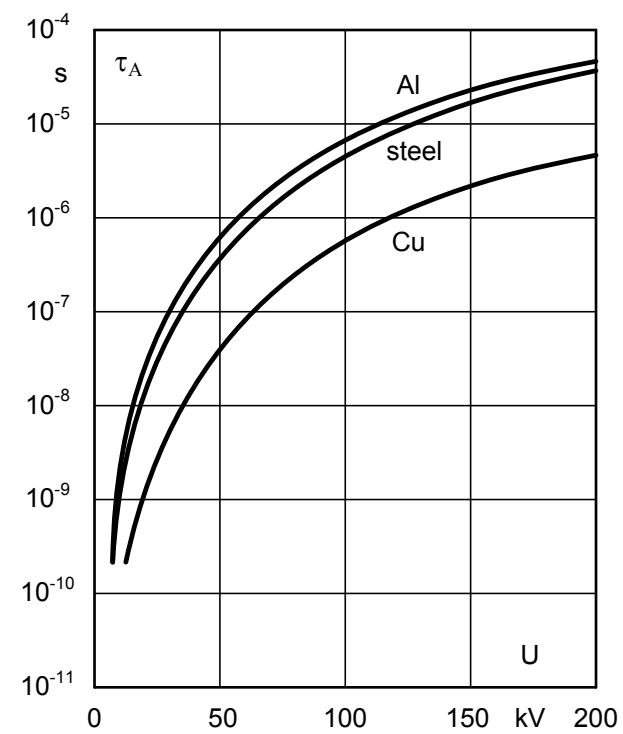

Fig. 2. Dependency of the time constants for the heating of the anode area (made of aluminium, steel or copper) bombarded with an electron beam, on the values of voltage at terminals of the vacuum-insulation system [1]

The delay time in the occurrence of the electrical breakdown in the vacuum insulation system, initiated by a micro-particle, is mainly caused by the time of its motion between the system electrodes. This time is much longer than that of other physical phenomena which the micro-particle initiates.

Based on work [2], calculations of the time of motion of spherical micro-particles made of copper and aluminium through a $5 \mathrm{~mm}$ vacuum gap were performed. The calculations were performed for $50 \mathrm{kV}$ and $100 \mathrm{kV}$ voltages. They demonstrated that in the case of the 50 $\mathrm{kV}$ voltage, the time of motion of copper micro-particles with radii of $0.1 \mu \mathrm{m}, 1 \mu \mathrm{m}$ and $10 \mu \mathrm{m}$ was $45 \mu \mathrm{s}, 143 \mu \mathrm{s}$ and $452 \mu \mathrm{s}$ respectively, and in the case of similar aluminium micro-particles $-25 \mu \mathrm{s}, 79 \mu \mathrm{s}$ and $250 \mu \mathrm{s}$.

In the year 1966, Tarasova [3] formulated the hypothesis regarding the desorption mechanism of initiating the electrical breakdown in vacuum. In that hypothesis, she concluded that at the pressure of $10^{-2} \ldots$ $10^{-5} \mathrm{~Pa}$, the surfaces of electrodes of the insulation system are covered with a layer of adsorbed gases.
Under the influence of high voltage, neutral particles and ions are desorbed from these surfaces. At a certain number of gas particles in the inter-electrode space, ionization and discharge development take place.

The likelihood of occurrence of this mechanism is reduced with the removal of adsorbed surface gases and pollution from system electrodes in the conditioning process. The time of the repeated total coverage of the vacuum-clean surface with the monomolecular layer of main air components - nitrogen and oxygen, may be determined based on the formula [4]

$$
\tau_{c} \approx 4 \cdot 10^{-5} T_{\mathrm{p}}^{1 / 2} p^{-1} \quad[\mathrm{~s}]
$$

where: $T_{\mathrm{p}}$ - surface temperature in $\mathrm{K}, p$-pressure in $\mathrm{Pa}$.

By means of formula (1), it was calculated that the time of the total coverage of the vacuum-clean surface with the temperature of $300 \mathrm{~K}$, with a monomolecular layer of nitrogen and oxygen at the pressure of $10^{-2} \mathrm{~Pa}$, amounts to about $0.07 \mathrm{~s}$, and at the pressure of $10^{-4} \mathrm{~Pa}-$ about $7 \mathrm{~s}$.

\section{Conclusions} paper:

The following conclusions can be drawn based on the 1. In vacuum insulation systems, with vacuum whose pressure is $10^{-2} \ldots 10^{-4} \mathrm{~Pa}$, tested with surge voltage, the role of the desorption mechanism in initiating the breakdown seems unquestionable.

2. While analysing the options for initiating the breakdown in the vacuum insulation system, at the a.c. voltage, by electron field emission, it is possible to make an attempt at indicating whether the breakdown in the given conditions is initiated by the cathode mechanism (the heating of the microprotrusion which emits an electron beam), or the anode mechanism (the heating of the anode area bombarded with an electron beam).

3. The delay time in the occurrence of the electrical breakdown in the vacuum insulation system, initiated by a micro-particle, is caused mainly by the time of motion of the micro-particle between the electrodes. For instance, at the voltage of $100 \mathrm{kV}$, the time of motion of spherical copper micro-particles with the radii of $0.1 \mu \mathrm{m}$, $1 \mu \mathrm{m}$ and $10 \mu \mathrm{m}$ through a $5 \mathrm{~mm}$ inter-electrode gap was $23 \mu \mathrm{s}, 72 \mu \mathrm{s}$ and $226 \mu \mathrm{s}$ respectively, and in the case of similar aluminium micro-particles - $13 \mu \mathrm{s}, 40 \mu \mathrm{s}$ and $125 \mu \mathrm{s}$.

\section{References}

1. W. Opydo, J. Ranachowski, Właściwości elektryczne próżniowych układów izolacyjnych przy napięciu przemiennym (WN PWN, Warsaw Poznan, 1993)

2. G. Twardosz, W. Opydo, K. Bieliński, Pozn. Univ. Technol. Acad. J. Electr. Eng 94, (2018)

3. L. V. Tarasova, Doklady AN SSSR 167 (1966)

4. A. Hałas, Technika próżni (Oficyna Wydawnicza Politechniki Wroclawskiej, Wrocław 2017) 